\title{
A framework to assess biogeochemical response to ecosystem disturbance using nutrient partitioning ratios
}

J. Marty Kranabetter, Ministry of Forests, Lands, and Natural Resource Operations, PO Box 9536 Stn Prov Govt, Victoria BC V8W 9C4, Canada Marty.Kranabetter@gov.bc.ca

Kendra K. McLauchlan, Department of Geography, Kansas State University, 118 Seaton Hall, Manhattan KS 66506, USA

Sara K. Enders, Department of Land, Air, \& Water Resources, University of California, One Shields Avenue, Davis CA 95616-8627, USA

Jennifer M. Fraterrigo, Department of Natural Resources and Environmental Sciences, University of Illinois, 1102 South Goodwin Ave, Urbana IL 61810, USA

Philip E. Higuera, Department of Forest Rangeland and Fire Sciences, University of Idaho, 875 Perimeter Drive, Moscow ID 83844, USA

Jesse L. Morris, Department of Forest, Rangeland, and Fire Sciences, University of Idaho, 875 Perimeter Drive, Moscow ID 83844, USA

Edward B. Rastetter, The Ecosystem Center, The Marine Biological Laboratory, 7 MBL Street, Woods Hole MA 02543, USA

Rebecca Barnes, Environmental Program, Colorado College, 14 E Cache La Poudre, Colorado Springs CO 80903, USA

Brian Buma, University of Alaska Southeast, 11120 Glacier Hwy, Juneau AK 99801, USA 
Daniel G. Gavin, Department of Geography, 1251 University of Oregon, Eugene OR 97403-1251, USA

Laci M. Gerhart, Department of Geography, Kansas State University, 118 Seaton Hall,Manhattan KS 66506, USA

Lindsey Gillson, Plant Conservation Unit, Department of Biological Sciences University of Cape Town, Private Bag X3 7701, South Africa

Peter Hietz, Institute of Botany, University of Natural Resources and Life Sciences, Gregor Mendel-Str.33, 1180 Vienna, Austria

Michelle C. Mack, Center for Ecosystem Science and Society, Northern Arizona University, PO Box 5620, Flagstaff AZ 86011, USA

Brenden McNeil, West Virginia University, Department of Geology and Geography, P.O. Box 6300, Morgantown WV 26506, USA

Steven Perakis, US Geological Survey, Forest and Rangeland Ecosystem Science Center, 3200 SW Jefferson Way, Corvallis OR 97331, USA 


\section{Abstract}

2 Disturbances affect almost all terrestrial ecosystems, but it has been difficult to

3 identify general principles regarding these influences. To improve our understanding of

4 the long-term consequences of disturbance on terrestrial ecosystems, we present a

5 conceptual framework that analyzes disturbances by their biogeochemical impacts. We

6 posit that the ratio of soil and plant nutrient stocks in mature ecosystems represents a

7 characteristic site property. Focusing on nitrogen $(\mathrm{N})$, we hypothesize that this

8 partitioning ratio (soil $\mathrm{N}$ : plant $\mathrm{N}$ ) will undergo a predictable trajectory after disturbance.

9 We investigate the nature of this partitioning ratio with three approaches: (1) nutrient

10 stock data from forested ecosystems in North America, (2) a process-based ecosystem

11 model, and (3) conceptual shifts in site nutrient availability with altered disturbance

12 frequency. Partitioning ratios could be applied to a variety of ecosystems and

13 successional states, allowing for improved temporal scaling of disturbance events. The

14 generally short-term empirical evidence for recovery trajectories of nutrient stocks and

15 partitioning ratios suggests two areas for future research. First, we need to recognize and

16 quantify how disturbance effects can be accreting or depleting, depending on whether

17 their net effect is to increase or decrease ecosystem nutrient stocks. Second, we need to

18 test how altered disturbance frequencies from the present state may be constructive or

19 destructive in their effects on biogeochemical cycling and nutrient availability. Long-

20 term studies, with repeated sampling of soils and vegetation, will be essential in further

21 developing this framework of biogeochemical response to disturbance. 
23 Keywords: Disturbance, fire regime, succession, Multiple Element Limitation (MEL)

24 model, nitrogen stocks, nutrient ratio 


\section{1. Introduction}

26 An ecosystem disturbance is a "relatively discrete event in time that disrupts

27 ecosystem, community or population structure and changes resource, substrate

28 availability, or the physical environment'" (Pickett and White 1985), which encompasses

29 both a wide variety of natural disturbance types (fires, storms, landslides, flooding,

30 volcanic eruptions) and terrestrial biomes (forest, grassland, alpine, deserts). The many

31 additional types of anthropogenic influences (pollution, intensive land-use practices,

32 climate change, and invasive species) which interact with and underscore global

33 environmental change highlight the need for a deeper understanding of disturbance

34 ecology (Peters et al. 2011). Yet disturbances are complex, individual events.

35 Characterizing a disturbance from a biogeochemical perspective aids in generalizations

36 about its outcomes because of the potential to integrate ecosystem processes over space

37 and time into metrics that ultimately control post-disturbance ecosystem trajectories

38 (Turner 2010). The challenge is building an adequate understanding of processes in key

39 abiotic and biotic parameters which more accurately predict the biogeochemical impacts

40 of single or multiple disturbance events.

41 Biogeochemical cycles of carbon (C) and nutrients exhibit a range of responses to

42 disturbance over ecologically meaningful time scales (Running 2008). In turn,

43 biogeochemical cycles and their interactions can influence the pattern and pace of

44 ecosystem recovery from disturbance; both disturbance legacies and feedbacks between

45 plant regrowth and soil element stores are particularly influential in shaping recovery

46 (Gough et al. 2007, Pearce et al. 2015). Feedbacks among C accumulation, nutrient

47 recycling, and other ecosystem processes may interact with whole-ecosystem constraints 
48 on element supply and loss (Belyea and Baird 2006). These constraints on the various

49 individual and feedback processes can result in surprisingly consistent patterns in

50 biogeochemical cycling after disturbance across a wide range of ecosystem types

51 (Davidson et al. 2007, Rastetter et al. 2013). Yet, key uncertainties remain in both the

52 consequences of disturbance events and their impacts at landscape scales. Thus it has

53 been difficult, for example, to quantify the direction and magnitude of biotic disturbances

54 on forest C cycling in the United States and Canada (i.e., Hicke et al. 2012). Nonetheless,

55 generalization of disturbance ecology would benefit from a theoretical biogeochemical

56 framework which would apply across single and multiple events, in multiple biomes.

57 For many terrestrial ecosystems, both the infrequent nature of disturbance events

58 and slow post-disturbance processes complicate efforts to empirically study

59 biogeochemical responses on long timescales. While a single disturbance event has the

60 potential to create a significant biogeochemical impact (Paré et al. 2002, Foster et al.

612003 , Romme et al. 2011), over the long term a shift in the disturbance regime itself and

62 its associated successional pathways may combine to affect ecosystems more profoundly

63 (e.g., directional change, Reiners 1983). Detecting shifts in disturbance regimes

64 necessitates extending the temporal scale of disturbance history beyond the time period of

65 direct or historical observations (Marlon et al. 2012). Recent studies have provided

66 increasingly clear characterizations of disturbance regimes (at least for fire and storm

67 regimes) on millennial timescales (Donnelly and Woodruff 2007, Higuera et al. 2014),

68 including return intervals, spatial extent and intensity (Baker 2009). Several lines of

69 evidence indicate incipient or ongoing shifts in disturbance regimes during the past few

70 decades, with larger and more frequent fire events (Dennison et al. 2014) and seemingly 
71 unprecedented bark beetle outbreaks (Raffa et al. 2008). Projecting the future

72 biogeochemical trajectory of disturbed systems requires the ability to identify how

73 profoundly a disturbance regime has departed from the present state (Walker and Wardle

74 2014).

75 Here, we introduce a conceptual framework using the ratio of plant and soil

76 nutrient stocks to characterize the relative stasis of mature ecosystems and to hypothesize

77 the consequences of a single disturbance event on nutrient loss and recovery. We suggest

78 this framework will improve ecosystem comparisons of biogeochemical response to

79 multiple disturbances over time. This framework is designed for temporal scaling and it is

80 flexible with regard to disturbance mechanism, ecosystem type, and spatial extent. We

81 develop this framework with three different approaches: (1) nutrient stock data from

82 forested ecosystems in North America, (2) a process-based ecosystem model, and (3)

83 conceptual shifts in site nutrient availability with altered disturbance frequency. We

84 expect that this framework will be sufficiently robust to improve our understanding of

85 biogeochemical outcomes across new disturbance types, regimes, and interactions.

\section{2. Characterizing terrestrial ecosystems by partitioning ratios}

87 In a mature terrestrial ecosystem (i.e., when aboveground biomass accumulation

88 has plateaued), nutrients are entrained into ecosystem cycles and accumulate

89 predominantly in soils and vegetation. For this accumulation to occur, a balance has to be

90 maintained between soil and plant processes; soil organic matter (SOM) cannot

91 accumulate without the litter produced by vegetation and the vegetation cannot grow and

92 continue to produce organic matter without the nutrients mineralized from the SOM. In

93 addition, the accumulation of nutrients has to be synchronized; $\mathrm{N}$ cannot accumulate in 
94 the ecosystem unless $\mathrm{P}$ and other vital nutrients also accumulate and vice versa. We posit

95 that the ratio between soil and plant nutrient stocks represents a characteristic property of

96 an ecosystem that can be quantified empirically, both to better allow cross-system

97 comparisons and to provide insight into the fluxes between pools (given that internal

98 cycling fluxes are often much larger than input and output fluxes) (Rastetter et al. 2013).

99 We call this value the partitioning ratio.

100 There is empirical support for characteristic differences in the partitioning ratio

101 among ecosystems at the biome scale. For illustrative purposes we focus our discussion

102 on nitrogen $(\mathrm{N})$, the most commonly limiting nutrient in terrestrial ecosystems, although

103 it should be recognized this element has unique characteristics such as significant organic

104 forms, multiple loss pathways, and multiple biotically-mediated transformations . As an

105 example, six types of North American forests ranging from boreal moist in British

106 Columbia to subtropical dry in Texas exhibit wide variability in soil N: vegetation $\mathrm{N}$,

107 spanning 1.3 to 40.9 across total soil $\mathrm{N}$ pools ranging from 724 to $6929 \mathrm{~kg} \mathrm{ha}^{-1}$ (Figure

108 1a) (Ponder et al. 2012). However, for the four forest types with sufficient sample size,

109 there are separate, unique values of soil N: vegetation N (Figure 1b). These results

110 suggest that boreal and temperate forested biomes as a whole may demonstrate consistent

111 and predictable partitioning ratios, at least in late successional stages.

112 This partitioning ratio concept may extend to other biomes beyond temperate

113 forests. For example, grasslands contain large belowground $\mathrm{N}$ stocks in the soil pool

114 relative to aboveground biomass. A prairie in Oklahoma (U.S.A.) had a partitioning ratio

115 of 232 over a three-year period in the 1970s (Risser et al. 1981). Deserts of the

116 southwestern U.S. generally have both low aboveground biomass and low soil organic 
117 matter stocks. Their $\mathrm{N}$ partitioning ratios range from 4 to 203 depending on the dominant

118 vegetation type [e.g. mesquite, sagebrush, creosote, and paloverde (West and Skujins

119 1978)]. Tropical forests with relatively organic-poor soils have low soil nutrient stocks

120 relative to vegetation nutrient stocks and exhibit partitioning ratios of 1.6 to 4.8 (Jordan

121 1985). Thus, the quantification of soil and plant nutrient stocks via a partitioning ratio

122 appears to be a useful characteristic descriptor of biomes.

\section{3. Single disturbance events and recovery of nutrient stocks}

124 Disturbance events can immediately and dramatically alter the ratio of soil and

125 vegetation $\mathrm{N}$ stocks, shifting the system away from the partitioning ratio. For example, a

126 wildfire on Alaskan tundra in 2007 changed the $\mathrm{N}$ partitioning ratio from 16.8 to nearly

127 infinity due to the complete combustion of aboveground biomass (Mack et al. 2011). It is

128 our contention that ecosystems undergo a predictable trajectory in recovery of nutrient

129 stocks and partitioning ratios during a return to the pre-disturbance condition over

130 secondary successional timescales (Jordan et al. 1972, Vitousek and Reiners 1975). The

131 ratio between soil and plant nutrient stocks represents a characteristic property of an

132 ecosystem such that over time, the internal and external factors affecting a given

133 ecosystem cause this ratio to be "attracted" (sensu Haeussler 2011) to a characteristic

134 value.

135 To illustrate, after a disturbance event we postulate a redistribution phase where

136 there is a net release of nutrients from soil and net accumulation by plants (Figure 2). If

137 the nutrient is limiting to growth during the recovery, the recovery trajectory will parallel

138 the isopleths of total ecosystem nutrient or be slightly above and to the right of those

139 isopleths if nutrient is also accumulated in the ecosystem as a whole. If the nutrient is not 
140 limiting during recovery, there will tend to be a net loss from the ecosystem and the

141 recovery trajectory will be below and to the left of the isopleths of total ecosystem

142 nutrient. This redistribution trajectory should approach the predisturbance baseline as

143 plant and soil processes come back into balance. Once the balance is reestablished, the

144 ecosystem will be more effective at entraining and retaining nutrients in the ecosystem

145 cycle and from that point on, the recovery trajectory should coincide with characteristic

146 partitioning ratio of the ecosystem. DeAngelis (1980) hypothesized that this recovery

147 time reflected system energetics, in particular the mean transit time of essential and

148 nonessential nutrients recycled between soils and vegetation during succession.

149 Several post-disturbance sampling sequences indicate some degree of predictable

150 temporal change in soil N: vegetation N over time (Johnson and Turner 2014). In

151 lodgepole pine forests of the Greater Yellowstone ecosystem, soil $\mathrm{N}$ and vegetation $\mathrm{N}$

152 stocks recovered at different rates during 331 years after stand-replacing fires, converging

153 on a characteristic partitioning ratio over time (Smithwick et al. 2009). In tropical

154 rainforests of the Andean foothills in western Amazonia, the partitioning ratio changed

155 from 39 at three years post-disturbance, to 7.25 at 25-30 years post-disturbance, relative

156 to a ratio of 2.2 in primary forest (Scott 1978). While we emphasize ratios because of the

157 balance struck between plant:soil nutrient cycles in the conceptual model, the absolute

158 amounts of ecosystem nutrient capital (isopleths in Figure 2) could also be a vital

159 measure of biogeochemical recovery under many applications.

160 The initial effect of a disturbance on the partitioning ratio and nutrient stocks

161 depends on the specific mechanism because the biogeochemical consequences of

162 disturbance events are not simply loss of nutrients. Disturbances can also increase 
163 ecosystem nutrient stocks or change their distributions among pools. This argues for the

164 need to expand current definitions of disturbance. Examples of disturbance increasing

165 nutrient stocks (either concurrent with the disturbance event or displaced over time)

166 include deposition of calcium-rich volcanic ash (Ayris and Delmelle 2012), post-fire N

167 fixation by early successional plants such as alder (Perakis et al. 2011), sediment

168 deposition during floodplain disturbances (Appling 2012), thermokarst delivery of

169 phosphorus (P) to tundra, or anthropogenic $\mathrm{N}$ additions (Block et al. 2012). These types

170 of accreting disturbance events are an important counterexample to the traditional view

171 of disturbance as reducing terrestrial ecosystem nutrient stocks.

172

173 4. Modeling nutrient stock recovery to a disturbance event across contrasting

174 ecosystems

175 To illustrate how ecosystems with differing partitioning ratios may recover $\mathrm{N}$

176 stocks following a disturbance event, we used the Multiple Element Limitation (MEL)

177 model with parameters as described by Rastetter et al. (2013) (Figure 3). The MEL model

178 was used to simulate three broadly contrasting ecosystems in the U.S.A.: (1) the mixed

179 deciduous and coniferous forest of Hubbard Brook Experimental Forest, located in New

180 Hampshire (Bormann and Likens 1979), (2) temperate wet coniferous forest of the H. J.

181 Andrews Experimental Forest in Oregon (Harmon 1992), and (3) Arctic tundra at the

182 Toolik Lake Long Term Ecological Research site in Alaska (Hobbie and Kling 2014).

183 We calculated the partitioning ratio for $\mathrm{N}$ (soil $\mathrm{N}$ : vegetation $\mathrm{N}$ ) at steady state for each

184 ecosystem. The partitioning ratios at Hubbard Brook, H. J. Andrews, and Toolik Lake

185 were 10.1, 5.5, and 52.7, respectively. A disturbance was simulated in the model by 
186 removing $90 \%$ of the aboveground biomass. To simulate a range of successional

187 pathways, $80 \%$ or $100 \%$ of the pre-disturbance biomass was added to the soil and coarse

188 woody debris pools following the disturbance event.

189 In all three modeled ecosystems there was a temporal trajectory of return to the

190 original partitioning ratio after the disturbance event but at greatly different rates because

191 the mechanisms of recovery differed among the three ecosystems (Figure 3). The

192 quantity of biomass returned to the system has a slight effect on the rate of recovery, but

193 recovery pathways are quite similar. Symbiotic $\mathrm{N}$ fixation is not thought to be a major

194 component of the recovery at Hubbard Brook or Toolik Lake, but it is a major contributor

195 to the $\mathrm{N}$ budget during the recovery at H.J. Andrews. Hence the N trajectory for H.J.

196 Andrews indicates a net gain of $\mathrm{N}$ by the ecosystem soon after the disturbance, which is

197 then lost during later stages of succession. Note that the recovery trajectories following

198 disturbance converge at a lower point in succession rather than returning directly to

199 predisturbance levels. This convergence results from the loss of nutrients in the

200 disturbance and in the early recovery phase. These nutrients need to be recovered before

201 the relative stasis of a mature ecosystem can be reached. There is potentially a high

202 capacity for predicting post-disturbance trajectories with this framework. In addition to

203 measuring the immediate effects of a disturbance (accreting or depleting in terms of any

204 given soil nutrient stock, such as a reduction in soil $\mathrm{N}$ ), the relative ratio change through

205 time could be predicted based on known successional ratio development.

207 5. Assessing biogeochemical vulnerability to disturbances 
The partitioning ratio could theoretically be used to predict biogeochemical

209 vulnerability to disturbances. Forest scientists have proposed analogous "stability ratios"

210 for ranking the sensitivity of sites to nutrient loss through disturbance and corresponding

211 vegetation removal (Himes et al. 2014). Conceptually, sites with proportionally greater

212 allocation of nutrients in vegetation are at risk of diminished productivity due to direct

213 losses through disturbance. Himes et al. (2014) postulated that forested sites with stability

214 ratios $<0.1$ have low risk, those with 0.1 to 0.3 have minor risk, those with 0.3 to 0.5

215 have significant risk, and those with $>0.5$ have an immediate and high risk of

216 productivity declines. In their analysis of forests in the Pacific Northwest, the areas with

217 the highest concentrations of at-risk sites were those with young, glacially derived soils.

218 Stability ratios have in many cases not been empirically confirmed, but this is an

219 area of active research through programs such as the Long-term Soil Productivity Study

220 (LTSP) (Powers 2006) and the Centre for International Forestry Research (Saint-André et

221 al. 2008). Over the first ten years of the LTSP study the complete site-level organic

222 matter removal treatment has not yet resulted in significant, overall declines in

223 regenerating stand productivity (Ponder et al. 2012), but early trends indicate some

224 differing sensitivities to nutrient loss by forest soil type (e.g., deeply weathered

225 subtropical soils vs. less developed glacial soils) that may corroborate the partitioning

226 ratio concept. More significant effects of nutrient capital removal may appear after

227 canopy closure, when regenerating forests place greater demands on soil nutrients

228 (Thiffault et al. 2011), but it is also possible that losses in nutrient stocks will result in

229 only temporary, rather than permanent, reductions in growth capacity as soil processes

230 recover (Egnell 2011). For example, recent studies in the Brazilian Cerrado 
231 forest/savanna ecotone suggest that less fertile sites are more sensitive to changes in fire

232 frequency, likely because fire-induced losses of nutrients greatly exceed the supply of

233 nutrients (de Dantas et al. 2013, Pellegrini et al. 2014). Alternatively, there is evidence

234 that tropical savannas are well adapted to fire (Bond 2008, Staver et al. 2011), and the

235 long-term nutrient balance of these biomes seems to not be altered, as $\mathrm{N}$ supply can keep

236 pace with losses from periodic, low intensity disturbance.

238 6. Stability of nutrient stocks under shifting disturbance frequencies

239 It might be argued that, as illustrated by the modeling exercise, a single

240 disturbance event may be less a question of 'if' nutrient stocks recover but rather a

241 question of 'when'. We suggest more fundamental alterations in nutrient stocks and

242 partitioning ratios may require changes in disturbance frequency or intensity over

243 multiple generations of a plant community (e.g., many decades for grasslands, many

244 centuries for forests). A number of mechanisms have been identified or hypothesized as

245 drivers in the biogeochemical response of ecosystems to disturbance frequency and

246 intensity (Gorham et al. 1979), such as bryophyte- and lichen-associated N-fixation,

247 water table fluctuations, mineral weathering rates, forest floor accumulations, and inputs

248 of ericaceous plant roots (Antoine 2004, Zackrisson et al. 2004, Simard et al. 2007,

249 Hazlett et al. 2011, Clemmensen et al. 2013). Quantification of these processes further

250 develops the concept of accreting or depleting disturbances by identifying mechanisms of

251 biogeochemical change. Both processes might even occur simultaneously, as in the

252 positive and negative aspects of forest floor accumulation and loss (Prescott et al. 2000).

253 The strength of these constructive and destructive processes may mean that shifts in 
254 disturbance frequency could push biogeochemical cycles to support either an altered

255 productive capacity of the ecosystem, or perhaps an entirely new, alternative stable state

256 (Reiners 1983).

257 We have conceptually portrayed these possible interactions of site properties with

258 disturbance frequency to illustrate how ecosystems may respond with increased,

259 decreased, or no change in long-term nutrient supply rates (Figure 4). Ecosystems

260 exhibiting low sensitivity to excessive disturbance (i.e. showing small changes in total

261 nutrient capital, point A in Figure 4) would theoretically have rapid vegetation recovery

262 with a significant component of $\mathrm{N}$-fixing plants, soils with high buffering capacity,

263 weatherable minerals for $\mathrm{P}$ and base cation replenishment, and a high allocation of site

264 nutrients in belowground pools. Ecosystems exhibiting high sensitivity to excessive

265 disturbance (point B) would be relatively slow to revegetate, highly prone to nutrient

266 leaching (high precipitation regime, low retention capacity of the soil) and nutrient

267 volatilization (deep, dry surface organic accumulations), low rates of symbiotic and

268 asymbiotic $\mathrm{N}$-fixation, highly weathered soils, and a high allocation of site nutrients in

269 aboveground pools. Ecosystems with low sensitivity to reduced disturbance frequency

270 (point C) would have efficient and sustainable nutrient cycling between soils and

271 vegetation (low loss rates), adequate on-going replenishment of sequestered nutrients (via

272 mineral weathering and $\mathrm{N}$-fixation), and balanced organic matter inputs (e.g., wood, litter,

273 roots, bryophytes) and outputs (decomposition). Mechanisms leading to a high sensitivity

274 to infrequent disturbances (point $\mathrm{D}$ ) would be excessive nutrient immobilization through

275 biomass sequestration, detrimental changes over time in soil thermal properties or

276 drainage (cooling via forest floor accumulations, paludification), reduced rhizodeposition, 
277 and high inputs of low-quality litter such as peat or ericaceous plants. These

278 characterizations of ecosystem properties and responses to multiple disturbances should

279 generate several testable hypotheses suitable for cross-biome synthesis.

\section{7. Conclusions}

281 - The partitioning ratio (soil $\mathrm{N}$ : vegetation $\mathrm{N}$ ) could be a useful and fundamental

282 characterization of terrestrial ecosystems, as well as a simple predictor of

283 ecosystem resilience to disturbance. More experimental evidence to identify

284 ecosystems that may be sensitive or insensitive to nutrient losses from

285 aboveground disturbance should be collected from a variety of ecosystems and

$286 \quad$ successional states.

- We suggest that classifying disturbances by their biogeochemical impacts may improve understanding of their long-term consequences on ecosystems.

Particularly, disturbances can be considered accreting or depleting depending on whether they increase or decrease nutrient stocks. Standardization of accretion or depletion will, in some cases, require consideration of return intervals, establishment of common timeframes for disturbance events, and assessment of typical spatial patterns to facilitate cross-biome comparisons.

- Sustainable management of forest, grassland and other terrestrial ecosystems over long time periods can be conceptualized and tested by considering how changes in disturbance frequency (e.g. livestock grazing intensity, forest plantation rotation age) might balance the accreting and depleting processes influencing soil nutrient availability. 
- Further development of this framework could focus on multiple elements in state space. Our modeling results indicate that the post-disturbance ecosystem trajectories reflect cycling rates and stoichiometry in plant and soil pools. Stoichiometry is also likely to be important in post-disturbance trajectories of the empirical partitioning ratio.

304 


\section{Acknowledgements}

306 We thank members of the Novus Research Coordination Network for helpful

307 discussion. We also thank the Long-term Soil Productivity network for contributions of

308 site N data, including Andy Scott, Dave Morris, Paul Hazlett, Rob Fleming, Deb Page-

309 Dumerose, Felix Ponder, Mary-Beth Adams, Richard Kabzems, Bill Chapman, and

310 Graeme Hope. This material is based upon work supported by the National Science

311 Foundation under Grant No. DEB-1145815 and 0949420. Bill Reiners and an anonymous

312 reviewer provided helpful comments on an earlier version of the manuscript. Any use of

313 trade names is for descriptive purposes only and does not imply endorsement by the US

314 Government.

315 


\section{References}

317 Antoine ME. 2004. An ecophysiological approach to quantifying nitrogen fixation by

$318 \quad$ Lobaria oregana. The Bryologist 107:82-87.

319 Appling AP. 2012. Connectivity drives function: carbon and nitrogen dynamics in a 320 floodplain-aquifer ecosystem. Duke University, USA. 190p.

321 Ayris PM, Delmelle P. 2012. The immediate environmental effects of tephra emission. $322 \quad$ Bulletin of Volcanology 74:1905-1936.

323 Baker WL. 2009. Fire ecology in rocky mountain landscapes. Island Press, Washington

324 DC, USA. 628p.

325 Belyea LR, Baird AJ. 2006. Beyond 'the limits to peat bog growth': cross-scale feedback

326 in peatland development. Ecological Monographs 76:299-322.

327 Block CE, Knoepp JD, Elliott KJ, Fraterrigo JM. 2012. Impacts of hemlock loss on

328 nitrogen retention vary with soil nitrogen availability in the southern Appalachian

329 Mountains. Ecosystems 15:1108-1120.

330 Bond WJ. 2008. What limits trees in C-4 grasslands and savannas? Annual Review of

$331 \quad$ Ecology Evolution and Systematics 39:641-659.

332 Bormann FH, Likens GE. 1979. Pattern and process in a forested ecosystem. Springer333 Verlag, NY, USA. 272p.

334 Clemmensen KE, Bahr A, Ovaskainen O, Dahlberg A, Ekblad A, Wallander H, Stenlid J, 335 Finlay RD, Wardle, DA, and Lindahl BD. 2013. Roots and associated fungi drive 336 long-term carbon sequestration in boreal forest. Science 339:1615-1618.

337 de Dantas VL, Batalha MA, Pausas JG. 2013. Fire drives functional thresholds on the 338 savanna-forest transition. Ecology 94:2454-2463. 
339 DeAngelis DL. 1980. Energy flow, nutrient cycling, and ecosystem resilience. Ecology

$340 \quad 61: 764-771$.

341 Davidson EA, de Carvalho CJR, Figueira AM, Ishida FY, Ometto JP, Nardoto GB, Saba

342 RT, Hayashi SN, Leal EC, Vieira IC, Martinelli L. 2007. Recuperation of nitrogen

343 cycling in Amazonian forests following agricultural abandonment. Nature

$344 \quad 447: 995-998$.

345 Dennison PE, Brewer SC, Arnold JD, Moritz MA. 2014. Large wildfire trends in the

346 western United States, 1984-2011. Geophysical Research Letters 41:2928-2933.

347 Donnelly JP, Woodruff JD. 2007. Intense hurricane activity over the past 5,000 years

348 controlled by El Nino and the West African monsoon. Nature 447:465-468.

349 Egnell G. 2011. Is the productivity decline in Norway spruce following whole-tree

350 harvesting in the final felling in boreal Sweden permanent or temporary? Forest

$351 \quad$ Ecology and Management 261:148-153.

352 Foster D, Swanson F, Aber J, Burke I, Brokaw N, Tilman D, Knapp A. 2003. The

353 importance of land-use legacies to ecology and conservation. Bioscience 53:77-88.

354 Gorham E, Vitousek PM, Reiners WA. 1979. The regulation of chemical budgets over

355 the course of terrestrial ecosystem succession. Annual Review of Ecology and

$356 \quad$ Systematics 10:53-84.

357 Gough C, Vogel C, Harrold K, George K, Curtis P. 2007. The legacy of harvest and fire

358 on ecosystem carbon storage in a north temperate forest. Global Change Biology

$359 \quad 13: 1935-1949$. 
360 Harmon ME. 1992. Long-term experiments on log decomposition at the H.J. Andrews Experimental Forest. PNW-GTR-280, U.S. Department of Agriculture, Forest Service, Pacific Northwest Research Station, Portland, Oregon. 28p.

363 Haeussler S. 2011. Rethinking biogeoclimatic ecosystem classification for a changing world. Environmental Review 19:254-277.

365 Hazlett, PW, Curry JM, Weldon TP. 2011. Assessing decadal change in mineral soil cation chemistry at the Turkey Lakes watershed. Soil Science Society of America Journal 75:287-305.

368 Hicke JA, Allen CD, Desai AR, Dietze MC, Hall RJ, Hogg EH, Kashian DM, Moore D, Raffa KF, Sturrock RN, Vogelmann J. 2012. Effects of biotic disturbances on forest carbon cycling in the United States and Canada. Global Change Biology

372 Higuera PE, Briles CE, Whitlock C. 2014. Fire-regime complacency and sensitivity to centennial-through millennial-scale climate change in Rocky Mountain subalpine forests, Colorado, USA. Journal of Ecology 102:1429-1441.

375 Himes AJ, Turnblom EC, Harrison RB, Littke KM, Devine WD, Zabowski D, Briggs DG.

376 2014. Predicting risk of long-term nitrogen depletion under whole-tree harvesting 377 in the Coastal Pacific Northwest. Forest Science 60:382-390.

378 Hobbie JE, Kling GW. 2014. Alaska's changing arctic: ecological consequences for 379 tundra, streams, and lakes. Oxford University Press, UK. 352p.

380 Johnson DW, Turner J. 2014. Nitrogen budgets of forest ecosystems: a review. Forest $381 \quad$ Ecology and Management 318:370-379. 
382 Jordan CF. 1985. Nutrient cycling in tropical forest ecosystems. John Wiley and Sons,

383 Chichester, UK. 190p.

384 Jordan CF, Cline JR, Sasscer DS. 1972. Relative stability of mineral cycles in forest

385 ecosystems. American Naturalist 106:237-253.

386 Mack MC, Bret-Harte MS, Hollingsworth TN, Jandt RR, Schuur EAG, Shaver GR,

387 Verbyla DL. 2011. Carbon loss from an unprecedented Arctic tundra wildfire.

$388 \quad$ Nature 475:489-492.

389 Marlon JR, Bartlein PJ, Gavin DG, Long CJ, Anderson RS, Briles CE, Brown KJ,

390 Colombaroli D, Hallett DJ, Power MJ, Scharf EA, Walsh MK. 2012. Long-term

391 perspective on wildfires in the western USA. Proceedings of the National

392 Academy of Sciences of the United States of America 109:E535-E543.

393 Paré D, Rochon P, Brais S. 2002. Assessing the geochemical balance of managed boreal

394 forests. Ecological Indicators 1:293-311.

395 Pearce AR, Rastetter EB, Kwiatkowski BL, Bowden WB, Mack MC, Jiang Y. 2015.

396 Recovery of Arctic tundra from thermal erosion disturbance is constrained by

397 nutrient accumulation: a modeling analysis. Ecological Applications, in press.

$398 \quad$ http://dx.doi.org/10.1890/14-1323.1

399 Pellegrini AFA, Hoffmann WA, Franco AC. 2014. Carbon accumulation and nitrogen

400 pool recovery during transitions from savanna to forest in central Brazil. Ecology

$401 \quad 95: 342-352$.

402 Perakis SS, Sinkhorn ER, Compton JE. 2011. Delta(15)N constraints on long-term

403 nitrogen balances in temperate forests. Oecologia 167:793-807. 
404 Peters DPC, Lugo AE, Chapin III FS, Pickett STA, Duniway M, Rocha AV, Swanson FJ,

405 Laney C, Jones J. 2011. Cross-system comparisons elucidate disturbance

406 complexities and generalities. Ecosphere 2:art81-art81.

407 Pickett STA, White PS. 1985. The ecology of natural disturbance and patch dynamics. $408 \quad$ Academic Press, NY, USA. 472p.

409 Ponder Jr. F, Fleming RL, Berch S, Busse MD, Elioff JD, Hazlett PW, Kabzems RD, 410 Kranabetter JM, Morris DM, Page-Dumroese D, Palik BJ, Powers RF, Sanchez

411 FG, Scott DA, Stagg RH, Stone DM, Young DH, Zhang J, Ludovici KH,

412 McKenney DW, Mossa DS, Sanborn PT, Voldseth RA. 2012. Effects of organic

413 matter removal, soil compaction and vegetation control on 10th year biomass and

414 foliar nutrition: LTSP continent-wide comparisons. Forest Ecology and $415 \quad$ Management 278:35-54.

416 Powers RF. 2006. Long-Term Soil Productivity: genesis of the concept and principles 417 behind the program. Canadian Journal of Forest Research 36:519-528.

418 Prescott CE, Maynard DG, Laiho R. 2000. Humus in northern forests: friend or foe?

$419 \quad$ Forest Ecology and Management 133: 23-36.

420 Raffa KF, Aukema BH, Bentz BJ, Carroll AL, Hicke JA, Turner MG, Romme WH. 2008.

421 Cross-scale drivers of natural disturbances prone to anthropogenic amplification:

422 the dynamics of bark beetle eruptions. Bioscience 58:501-517.

423 Rastetter EB, Yanai RD, Thomas RQ, Vadeboncoeur MA, Fahey TJ, Fisk MC,

424 Kwiatkowski BL, Hamburg SP. 2013. Recovery from disturbance requires

425 resynchronization of ecosystem nutrient cycles. Ecological Applications 23:621-

$426 \quad 642$. 
427 Reiners WA. 1983. Disturbance and basic properties of ecosystem energetics. Mooney

428 HM, Gordon M, editors. Disturbance and ecosystems: components of response.

429 Ecological Studies Volume 44, Springer Verlag. p83-98.

430 Risser PG, Birney EC, Blocker HD, May SW, Parton WJ, Wiens JA. 1981. The true

431 prairie ecosystem. Academic Press, Stroudsburg, PA, USA. 557p.

432 Romme WH, Boyce MS, Gresswell R, Merrill EH, Minshall GW, Whitlock C, Turner

433 MG. 2011. Twenty years after the 1988 Yellowstone fires: lessons about

434 disturbance and ecosystems. Ecosystems 14:1196-1215.

435 Running SW. 2008. Ecosystem disturbance, carbon, and climate. Science 321:652-653.

436 Saint-André L, Laclau J-P, Deleporte P, Gava JL, Gonçalves JL, Mendham D, Nzila JD,

437 Smith C, duToit B, Xu DP, Sankaren KV, Marien JN, Nouvellon Y, Bouillet J-P,

438 Ranger J. 2008. Slash and litter management effects on Eucalyptus productivity: a

439 synthesis using a growth and yield modelling approach. Nambiar EKS, editor.

$440 \quad$ Site management and productivity in tropical plantation forests: workshop

441 proceedings, 22-26 November 2004, Piracicaba, Brazil and 6-9 November,

442 Bogor, Indonesia. Center for International Forestry Research, Bogor, Indonesia.

$443 \quad$ p173-189.

444 Scott GAJ. 1978. Grassland development in the Gran Pajonal of eastern Peru. University 445 of Hawaii, USA. 185p.

446 Simard M, Lecomte N, Bergeron Y, Bernier PY, Paré D. 2007. Forest productivity

447 decline caused by successional paludification of boreal soils. Ecological

$448 \quad$ Applications 17:1619-1637. 
449 Smithwick EAH, Kashian DM, Ryan MG, Turner MG. 2009. Long-term nitrogen storage

450 and soil nitrogen availability in post-fire lodgepole pine ecosystems. Ecosystems

$451 \quad 12: 792-806$.

452 Staver AC, Archibald S, Levin SA. 2011. The global extent and determinants of savanna 453 and forest as alternative biome states. Science 334:230-232.

454 Thiffault E, Hannam KD, Paré D, Titus BD, Hazlett PW, Maynard DG, Brais, S. 2011.

455 Effects of forest biomass harvesting on soil productivity in boreal and temperate

456 forests - A review. Environmental Reviews 19:278-309.

457 Turner MG. 2010. Disturbance and landscape dynamics in a changing world. Ecology

$458 \quad 91: 2833-2849$.

459 Vitousek PM, Reiners WA. 1975. Ecosystem succession and nutrient retention: a $460 \quad$ hypothesis. Bioscience 25:376-381.

461 Walker LR, Wardle DA. 2014. Plant succession as an integrator of contrasting ecological 462 time scales. Trends in Ecology \& Evolution 29:504-510.

463 West NE, Skujins JJ. 1978. Nitrogen in desert ecosystems. Academic Press, Stroudsburg, $464 \quad$ PA, USA. 307p.

465 Zackrisson O, DeLuca TH, Nilsson M-C, Sellstedt A, Berglund LM. 2004. Nitrogen

466 fixation increases with successional age in boreal forests. Ecology 85:3327-3334. 467 

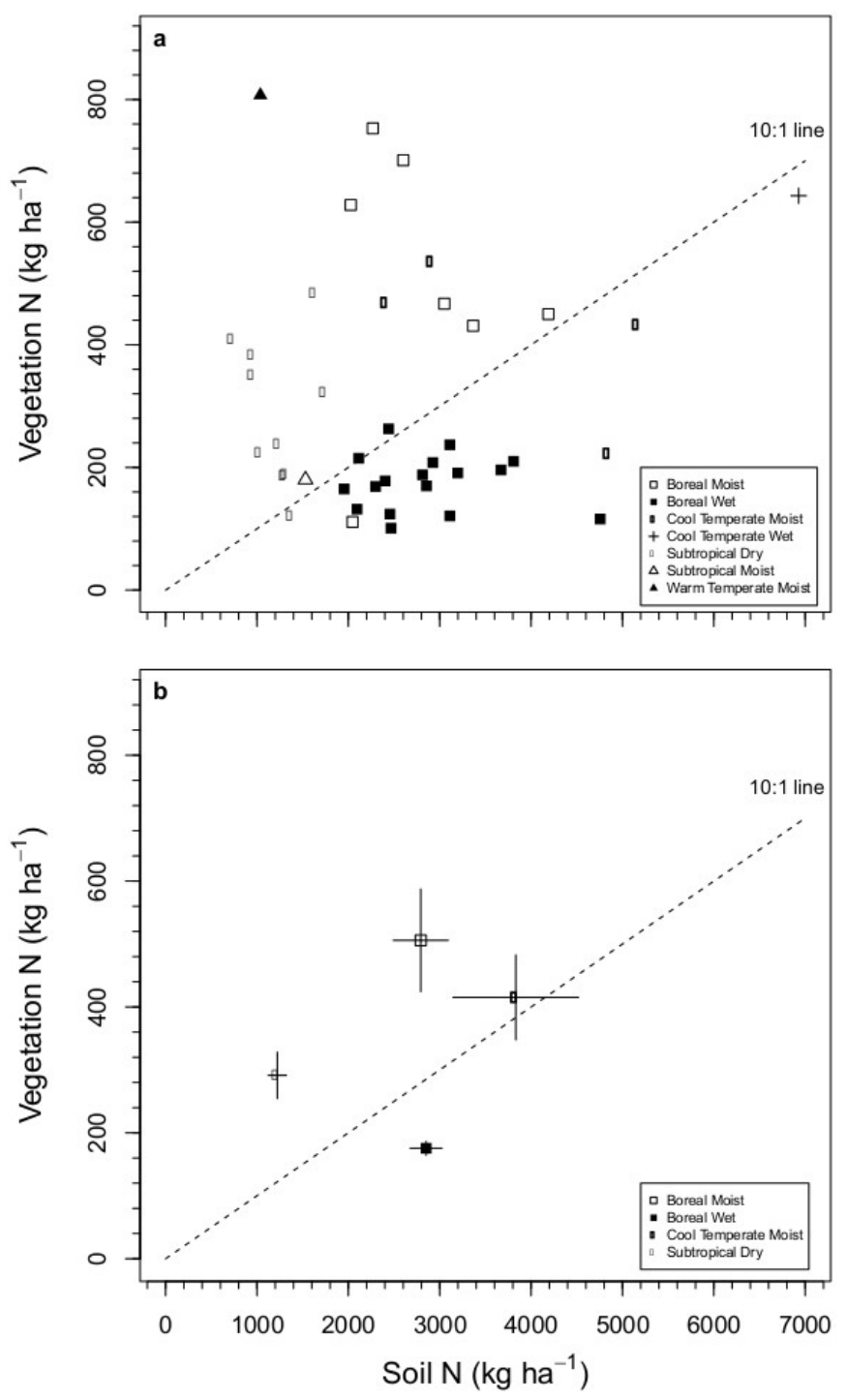

468

469 Figure 1. a) Ratios of soil $\mathrm{N}$ and vegetation $\mathrm{N}$ pools in 41 forests in North America that

470 are part of the Long-Term Soil Productivity network (Ponder et al. 2012). b) Mean values

471 for four Holdridge life zones with one standard error for both soil and vegetation N.

472 Vegetation $\mathrm{N}$ includes both tree bole and tree crown $\mathrm{N}$, while soil $\mathrm{N}$ includes both $\mathrm{O}$

473 horizon and mineral soil $\mathrm{N}$ measured to $20 \mathrm{~cm}$ depth. Sites represent a variety of

474 successional stages, climate types, and dominant species. Locations: British Columbia,

475 Ontario, Louisiana, Mississippi, Texas, Washington, Missouri, North Carolina, and Idaho. 


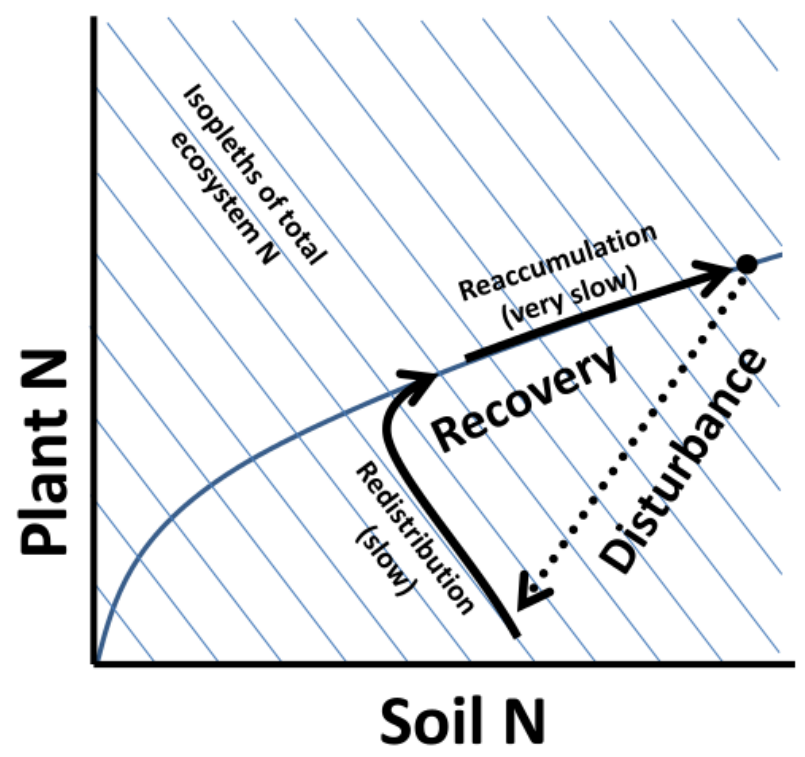

476

477 Figure 2. Plant nitrogen $(\mathrm{N})$ and soil $\mathrm{N}$ plot illustrating theoretical trajectories of nutrient 478 recovery after disturbance to re-establish characteristic partitioning ratios of an ecosystem.

479 The trajectory of succession in the plot proceeds up and toward the right as the ecosystem

480 accumulates nutrient. The exact trajectory will depend on the local environmental

481 conditions (climate, parent material, topography, potential biota), but because of the slow

482 rate of nutrient accumulation, the plant and soil process will remain in balance. Isopleths

483 of total nutrient in the ecosystem (vegetation and soil, assuming negligible nutrient

484 content in other ecosystem components) are diagonal lines in this plot. 485 

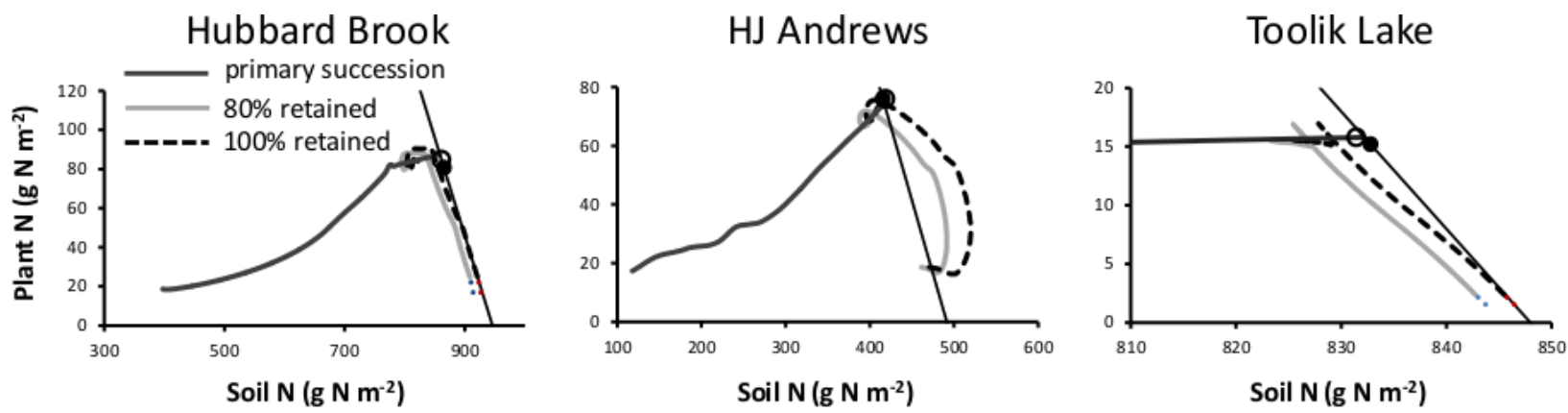

487 Figure 3. Trajectory of $\mathrm{N}$ recovery in vegetation versus soil following disturbance at the

488 Hubbard Brook, H.J. Andrews, and Toolik Lake LTER sites as predicted by the Multiple

489 Element Limitation (MEL) model. The filled circles are the assumed steady state values

490 for each ecosystem (to which the model was calibrated). The thin black lines are isopleths

491 of constant total ecosystem $\mathrm{N}$ (soil + plant $\mathrm{N}$ ). The solid lines represent the trajectory of

492 recovery following a $90 \%$ removal of vegetation biomass with either $80 \%$ or $100 \%$ of

493 that removed biomass added to the soil and coarse woody debris pools. Points above and

494 to the right of the line have more $\mathrm{N}$ than the steady state and points below and to the left

495 have less.

496 


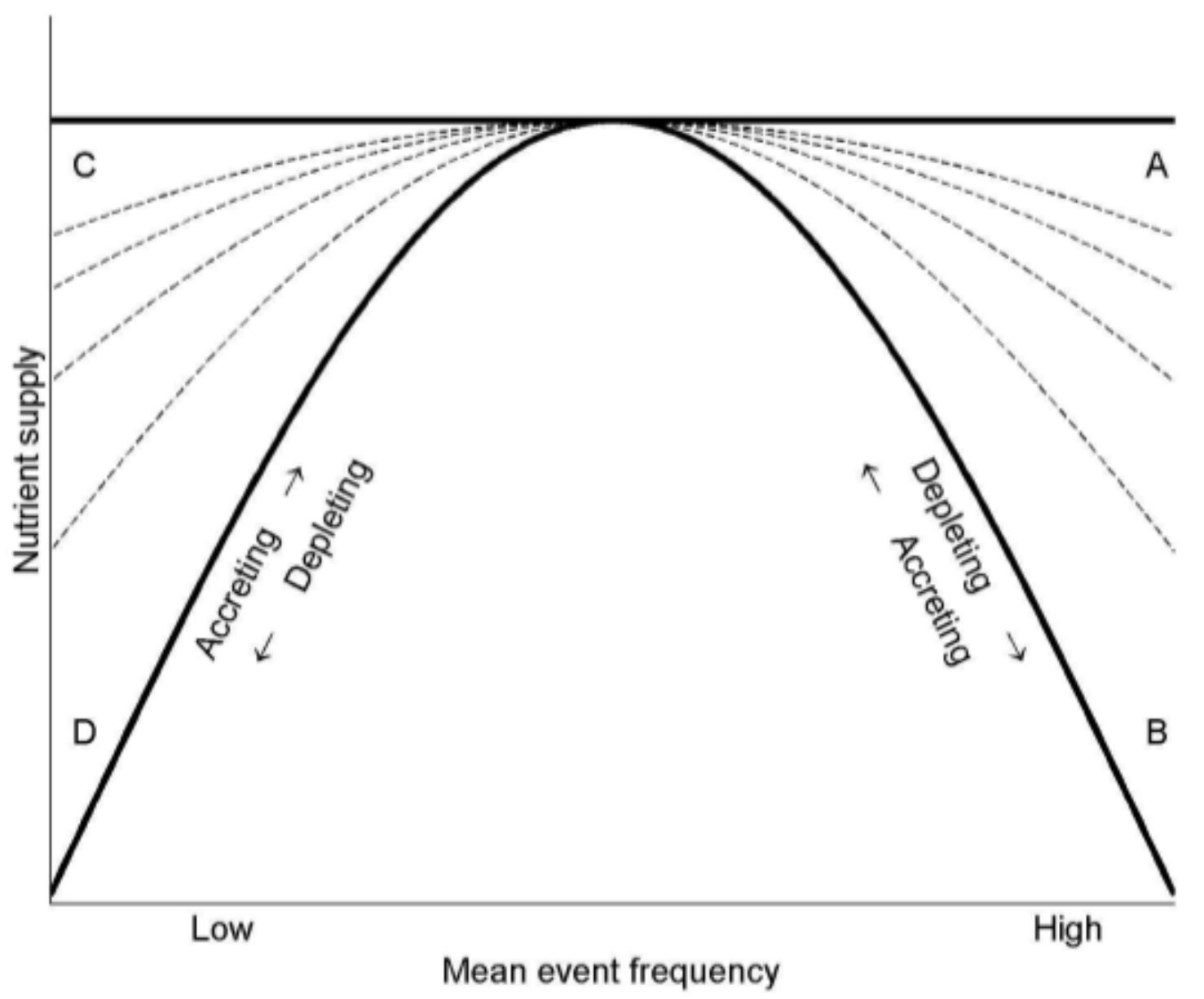

498 Figure 4. Conceptual figure of how disturbance frequency can balance the potentially

499 accreting and depleting processes affecting ecosystem nutrient capital. Projected response

500 ranges from complete loss (lower portion of the converse black curve) to no effect (top,

501 flat black line) of disturbance frequency on nutrient supply. Points A through D represent

502 four contrasting ecosystem responses as described in the text; for example, a coniferous

503 forest that requires a sufficient return interval of fire to sustain productivity because

504 nutrients immobilized in stand biomass and forest floors of old-growth are released for a

505 new cycle of growth (left side of the black curve moving towards the center, marked D).

506 Higher fire frequency, however, could be destructive (moving from center to the right

507 side of the black curve, marked B) because nutrients are depleted faster than they can be 
508 replaced, thereby lowering ecosystem productivity. Every ecosystem and site type could

509 occupy a unique spot in the conceptual figure, helping researchers formulate specific

510 hypotheses on how disturbance frequency may be constructive, destructive or of no

511 consequence to nutrient supply and ecosystem productivity. 